\title{
Experimental Zoology in Poland.
}

WE have recently received several volumes of the Bulletin International de l'Académie Polonaise des Sciences et des Lettres covering the period June 1922-May I924. The following notes based on communications in the Bulletins will serve to indicate some of the activities of workers in Poland in the field of experimental zoology during this period.

In " L'hérédité dans les cellules végétatives au cours de la régénération chez l'axolotl" (Bulletin, June 1922) Godlewski records his endeavours to discover whether somatic cells as distinct from genital cells preserve their inborn characters when transported to a new environment, or whether in such circumstances they " acquire" new characters. He transplanted a small piece of the skin of a black axolotl to a previously prepared spot on the base of the tail of an albino axolotl from which he had removed the skin. The new graft effected a satisfactory union with the neighbouring tissues and the animal was kept alive for five years. After the graft had united with the neighbouring skin, the tail was removed by a cut passing through the graft, and in about six months a new tail had been completely regenerated.

It is obvious that the grafted skin would necessarily take part in forming the new skin covering the regenerated tail, and the question was whether the new cells produced from the black skin would remain black or not. It was found that as the tail grew a black band of skin extended from the graft towards the tip of the tail; but that as time went on this band became narrower, and finally, after about two years, completely disappeared; but the area covered by the original graft maintained its black colour. Hence Godlewski concludes that the new cells derived by division from the black cells of the graft retain for a time their "inborn" black character, but that as time goes on their descendants slowly " acquire" the albino character of their environment and transmit this new character to their later descendants.

The original graft alters its position somewhat and moves slowly towards the base of the tail, but does not achieve more than a moderate change of position. This puzzling fact Godlewski explains by the assumption that in regeneration the skin grows more quickly than the other tissues, and so glides over them towards the tip of the tail.

Godlewski obtained a different result when he grafted a piece of skin from an albino axolotl on a wound in the base of the tail of a black axolotl. In this case the grafted piece of white skin soon assumed the colour of its black surroundings. This is explained by assuming that the skin chromatophores from the surrounding black skin migrate into the graft and change its colour.

$Z$. Kolodziejski has a paper on "Studies on the Metabolism of the Budding Hydra" in the Bulletin for October I6, 1923. In some cases of budding, as for example in Annelida, it has been shown that physiological differentiation is subsequent to morphological differentiation. Thus the reaction of the front part of the gut of an Annelid is acid whilst that of the remainder is basic, but the whole alimentary canal of the bud is basic in its reaction until its development is complete, and then alone physiological differentiation sets in. The primary object of the author was to discover whether similar differences in capacity existed between the mother Hydra and its immature buds.

The bud of Hydra is not formed as a simple eversion of the body-layers of the mother. It originates as a local thickening of the interstitial cells of the ectoderm, which penetrate between the neighbouring ectoderm cells and, after having pierced the supporting lamella, between the endoderm cells also. These young cells gradually become transformed into ordinary ectoderm and endoderm cells, and the mass becomes hollowed out and forms a young bud.

When Hydra is fed on food coloured with Sudan red or on naturally coloured food such as green infusoria, the fate of the food can be followed. The author in this way confirms previous accounts to the effect that the food is first partially dissolved and converted into an emulsion with solid particles by the action of ferments secreted by special gland cells. Thus the contents of insect larvæ provided with hard chitinous coverings such as those of Chironomus or Corethra are dissolved out. The particles.are afterwards ingested by amœboid action on the part of the large endoderm cells. The use of colour indicators proves that the endoderm cells have a basic reaction. All the endoderm cells both of mother and bud are equally active, and the particles of the food emulsion penetrate even into the tentacles, especially into those of the bud, which have wider internal openings than those of the mother.

When a brown Hydra is fed on the green infusorian Euglena, the chlorophyll is ingested by the endoderm cells and the animal appears like a green Hydra; but the chlorophyll is finally completely digested and disappears. Hydra can be induced to ingest fat by mixing it with protein; the fat globules afterwards appear in the endoderm cells but are very slowly dissolved. Starch is at once rejected as indigestible material. The brown granules of the ordinary Hydra, which give to it its characteristic colour, are of an excretory nature. They have a crystalline character which is revealed when they are examined by polarised light. They are not influenced by alcohol, ether, or chloroform, but yield slowly to the action of Io per cent. solutions of caustic potash and soda, and of hydrochloric, nitric, and sulphuric acids. The author considers that they are probably allied to guanin. After solution the colour remains as an amorphous mass, and is to be looked upon as another substance which is being excreted along with the supposed guanin.

S. Skouron in " Le Rapport plasmo-nucléaire pendant la Spermatogenèse chez Helix pomatia " (Bulletin, May 1924) examines the question whether there might be an emission of nuclear substance into the spermatogonia of Helix. He preserved the ovo-testes in corrosive sublimate and acetic, and determined by comparison with living material that this preservation produced no change in the nucleo-plasmic relation.

The youngest spermatogonia had large vesicular nuclei with a very fine spireme of chromatin. As the cell grows this spireme thickens and becomes contracted into a closely woven tangle of chromatin at one side of the nucleus. This stage is of course that of "synapsis." Afterwards the tangle loosens, distinct chromosomes appear, and the nucleus and cell divide into two. The later generations of spermatogonia are distinguished by their larger size, and by the fact that even in the resting nucleus the chromatin can be seen as thickenings of the nuclear network. There is always a "yolk-nucleus" or "Nebenkern" in the protoplasm at the side of the nucleus. The period of growth is terminated by the formation of the spermatocytes of the first order, distinguished by their comparatively large size and by the arrangement of the chromatin material in tetrads. The spermatocytes, by the reducing or meiotic division, become spermatocytes of the second order; by another division following immediately on this, each 
spermatocyte forms two spermatids. These are much smaller cells with nuclei filled with large and small granulations of chromatin. The spermatids by a series of well-known changes are converted into the spermatozoa.

The proportion of plasma to nucleus in young spermatogonia is about $2 \cdot 3-\mathrm{I}$; but in spermatogonia in which synapsis has set in, it varies from I-I (equality) to $0.7-1$. These figures indicate an enormous growth of nuclear matter which can actually exceed in bulk the remaining plasma. But if we follow the proportion between protoplasm and nucleus in subsequent generations of spermatogonia, we find that this in the first succeeding generations rises to $2 \cdot 5-I$ and in the later generations increases to $5 \cdot 3$ - I. As the latest generations of spermatogonia are changed into spermatocytes of the first order, this proportion rises to $6.8-\mathrm{I}$. After the formation of the spermatids, and during the growth of these, the proportion rises to $\mathrm{I} 9-\mathrm{I}$.

In the spermatogenesis of Helix there often occur polynuclear cells each of which gives rise to several spermatozoa. These cells result simply from nuclear division unaccompanied by cell division. If we compare the relation of protoplasm to nucleus in these cells we find that it runs through a series of changes parallel to those undergone by the plasmo-nuclear relation in normal spermatogonia. During the whole period of development of the sperm cells there is never any evidence of the emission of chromatinic substances from the nucleus into the protoplasm such as occurs in the egg.

Jean Prüffer contributes an interesting paper on "Observations and Experiments on the Phenomena of the Sexual Life of Lymantria dispar" (Bulletin, January 8,1923$)$. The pairing impulse becomes active as soon as the imagos of the Gipsy-moth emerge from their cocoons, and since a large number of chrysalides are found on the trunk of the same tree and the males emerge first, the latest males to emerge fertilise the first females. But a great deal of pairing occurs during the subsequent lives of the insects; and to accomplish it the males fly long distances, their flights occurring only by day. The females, though inactive by day, fly about at night.

Experiments proved that the males were able to seek and find the females, when their eyes were covered with an opaque substance, when their wings were removed, when one entire antenna was removed, and when the distal portions of both antennæe were removed. When both antennæ, however, were entirely removed, the males were unable to find the females even when their eyes were uncovered. It is obvious, therefore, that the sense organs which serve to detect the female must be situated in the basal portion of the antenna, and we may remember that it was in this region that Mr. K. M. Smith, of the Imperial College of Science, now at the University of Manchester, discovered and described highly developed sensory pits in flies.

The attractiveness of the female for the male was not diminished by the removal of the " scales" from the female's wings, nor by the removal of its wings, nor by the amputation of the two antennæ; but it was diminished and rendered uncertain by the removal of the scales from the abdomen, and entirely destroyed by the amputation of the abdomen. On the other hand, the amputated but otherwise uninjured abdomens of females were as attractive as the uninjured insects. It is obvious, therefore, that the hedonic scent which emanates from females and attracts males is localised in the abdomen and especially in the scales covering the genital region.

It has been shown that in newly hatched pigeons the liver and pancreas increase rapidly in weight, and that their rate of increase is out of all proportion to the increase of weight in the animal. Nevertheless in sections, no signs of either mitotic or of amitotic division of cells is to be seen. In the full-grown animals the liver and pancreas decrease in weight. In order to investigate this matter further, young pigeons were killed on the first, third, and fifth days after hatching and thereafter on every second day until full size was attained. The liver and pancreas were weighed in each bird thus examined and portions of these organs fixed and sectioned. (" Cell Growth and Body Growth Investigations in Pigeons," by L. Kaufmann. Bulletin, April I924.)

It transpires that the cell volume increases most rapidly between the first and third day (about 50 per cent.). Between the third and fifth day the rate of growth decreases, and on the ninth dav the cells are actually smaller, a proof that cell division has taken place. The nucleus undergoes its greatest growth during the first two days, but in seven-day old pigeons it is only as large as nuclei in one-day old pigeons, and in still older pigeons it is even smaller, so that from the ninth day there may be said to be a permanent shift of the nucleo-plasmic relation in favour of the plasma. In one-day old pigeons the plasma exceeds the nucleus in volume $12 \cdot 4$ times, but in the fullgrown bird the volume of the plasma is 66 times greater than the nucleus. After the seventh day, the number of karyokinetic figures diminishes and the increase in volume of cells is roughly proportionate to the increase in weight of the whole organ. As the liver is a storage organ, its weight increases with feeding and diminishes during fasting more than does the weight of the body as a whole. The decrease in weight of the liver in old birds is associated with a diminution in cell plasma.

In the growth of the pancreas, similar phenomena were observed, but the following differences are to be noted. The liver cell of the adult has five times the volume of the liver cell of the one-day old bird, but the pancreas cell of the adult is only twice the volume of the corresponding cell in the one-day old bird. The highest curve of increasing weight in the pancreas corresponds to the lowest curve of increase in cellvolume, whereas in the liver the lower curve of increase in liver weight corresponds to the higher curve of cell growth.

The author concludes that the nucleo-plasmic ratio has not, as had been previously supposed, a fixed point of equilibrium for each species, but that with each change in the general physical condition the nucleo-plasmic area may undergo alteration. Further, increase in volume and weight may be due to increase in amount of deutoplasmic substances and not of plasma.

Since Urodela are probably the most primitive land vertebrates now surviving, the mode of development of their blood-vessels, as indeed of their other organs, becomes a matter of interest and importance. This development had previously not been satisfactorily traced back to a sufficiently early stage of development; former authors relied mainly on sections, but Z. Grodinski (" ivber die Entwicklung der Gefässe des Dotterdarmes bei Urodelen," Bulletin, February II, I924) has made successful injections of exceedingly young larvæ beginning with those only $4.5 \mathrm{~mm}$. long.

These "larvæ" are really embryos with the tail and head merely indicated. In this youngest stage the main blood-vessels arise as metamerically arranged transverse branches from the aorta which unite with one another on either side to form a longitudinal vein at the level of the ventral edges of the myotomes,

NO. 29I8, VOL. II6] 
which the author terms the vena mesenterica. From this vena mesenterica, further transverse vessels arise running half-way round the yolky gut and uniting on each side in its ventro-lateral region to form another longitudinal vessel, which are termed the vena omphalo-mesenterica. In older larvæ $(5.5 \mathrm{~mm}$. in length) these two omphalo-mesenteric veins unite to form a single median sub-intestinal vein, which loses itself in the liver in front, and behind is continuous with the caudal vein. The venæ mesentericæ open into this sub-intestinal vein in front.

When the larva has attained a length of $7 \mathrm{~mm}$. the yolk begins to disappear rapidly and the gut consequently to shrink in diameter. The vena mesenterica of each side moves in a dorsal direction, and so approaches its fellow. The two become connected by transverse anastomoses and finally fuse into one. This single vein in the region of the duodenum describes a loop and fuses with the sub-intestinal vein. The transverse branches connecting it with the subintestinal vein become transformed into a network enwrapping the intestine. Those branches which connected it with the aorta disappear. The hinder end of the sub-intestinal vein now disappears, and finally only a small anterior portion of it remains where it receives the mesenteric vein. The posterior cardinal veins begin as vessels draining the developing pronephros on each side. These gradually extend backwards until they reach and unite with the caudal vein and drain off its blood, and it is this new connexion which leads to the disappearance of the sub-intestinal vein.

\section{The Source of the Cold Air of the North "Polar Front." 1}

By Prof. W. H. Новвs, University of Michigan.

DENUDED of its liquid envelope, the figure of the earth may be compared to that of a tomato having a flat lump affixed at one side of the depression from which the stem has been removed. Not a close parallel-even a caricature--but I trust a true one, and successful caricatures are full of meaning. It is necessary to place the tomato in such position that the depression represents the deep basin of the Arctic Ocean, the bulging portion which is opposite will then represent the flat ice-dome of the Antarctic continent, and the artificial lump beside the depression the entirely similar though somewhat smaller ice-covered continent of Greenland. Both of these domes rise to elevations of nearly two miles above sea.

No adequate treatment of the atmospheric circulation is possible unless account be taken of this unsymmetrical figure of the earth; though, curiously enough, it has been the rather general custom to discuss the circulation of the atmosphere as though the areas surrounding the two ends of the earth's axis were characterised by exactly similar conditions. The theory of Ferrel, and the newer conception of Bjerknes which seems to have taken its place, alike ignore the contrast which exists between the two polar regions.

Bjerknes, in reviving an older view of von Helmholtz, has assumed that because of exceptionally high irradiation about both poles of the earth there must be formed about them caps of cold air with corresponding areas of high pressure; and that this cold air must pour out in all directions and meet the warmer air from the equatorial regions upon a surface of discontinuity--the " polar front."

Of the existence of a source of cold air within high latitudes, and the families of cyclones associated with it which the Bjerknes, father and son, have made known in a series of brilliant monographs, it is impossible to doubt. The individual characteristics of the cyclones composing a family within which youthful characteristics and notably turbulence are found curiously reversed, the crescendo of vigour which they display in sequence, and the abruptness with which the series comes to an end-these discoveries must be accounted as very important contributions to meteorology.

It is the field to which Bjerknes's keen research has not been directly extended, but within which the chief foundation of his theory has been laid, toward which I now direct attention. Is the north polar region one of high atmospheric pressure from which cold air is poured outwards ? Fortunately the data 1 Paper presented to Section E (Geography) of the British Association
at Southampton on August 28.

No. 2918 , vOL. II6] for a satisfactory answer are present, and the decision must be in the negative.

We may perhaps conveniently limit the north polar region by the parallel of $80^{\circ} \mathrm{N}$., which will bring within it the entire Arctic Ocean for the sectors facing Europe and eastern North America, and will include upon its margins relatively small portions only of the land masses which in part bound that ocean. So far as explored, and with little doubt throughout, this entire area is deep sea covered with floating ice-cakes, which are continually drifting and which in no case rise more than a few tens of feet above the surface of the sea.

During the years I894-96 the Fram drifted far into this region, and for the entire calendar year I 895 , when the ship was nearest the Pole, it zigzagged along the $85^{\text {th }}$ parallel of latitude. The mean daily atmospheric pressure for this year based upon complete data was $76 \mathrm{I} \mathrm{mm}$., with very slight seasonal or monthly range of pressure. Mohn, who discussed the meteorological data on the basis of the entire drift, ${ }^{2}$ wrote: "The pressure at the North Pole seems to have its maximum-about $764 \mathrm{~mm}$.-in April, and minimum-759 mm.-from June to September. This gives an annual range of only $5 \mathrm{~mm}$." As I have divided the cruise, for the calendar year I 894 during which the Fram zigzagged between latitudes $79^{\circ}$ and $84^{\circ} \mathrm{N}$., the mean annual pressure was $75^{8} \mathrm{~mm}$. ; and for the seven months of 1896 , which were about equally divided between winter and summer, during which the vessel ranged in position from lat. $85^{\circ}$ to $8 \mathrm{I}^{\circ} \mathrm{N}$., the corresponding figure was also $75^{8} \mathrm{~mm}$.

These essentially normal figures obtained for the mean annual atmospheric pressure of the north polar region are, moreover, confirmed by the observations made by other explorers within the region or very close to its border, as the following figures will show

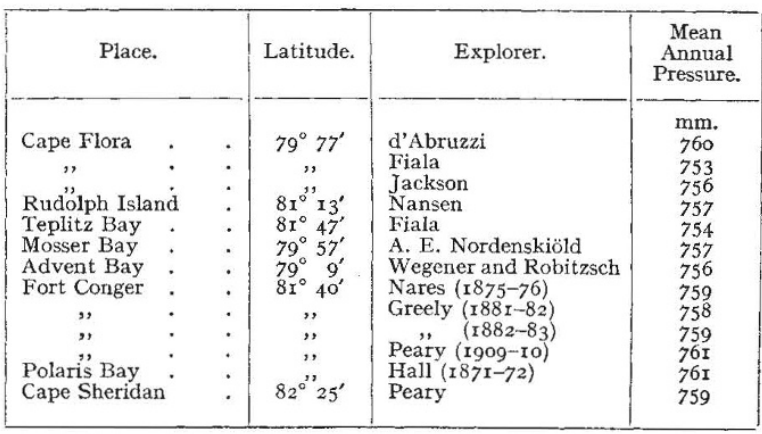

${ }^{2}$ H. Mohn, The Norwegian North Polar Expedition, 1893-96, Scientific Results, edited by Fridtjof Nansen, vol. 6, London, r905, Meteorology, p. 572 . 